\title{
The Embodiment Hypothesis
}

\section{Citation}

Jorgenson, Dale W. 1966. The embodiment hypothesis. Journal of Political Economy 74(1): 1-17.

\section{Published Version}

http://dx.doi.org/10.1086/259105

\section{Permanent link}

http://nrs.harvard.edu/urn-3:HUL.InstRepos:3403063

\section{Terms of Use}

This article was downloaded from Harvard University's DASH repository, and is made available under the terms and conditions applicable to Other Posted Material, as set forth at http:// nrs.harvard.edu/urn-3:HUL.InstRepos:dash.current.terms-of-use\#LAA

\section{Share Your Story}

The Harvard community has made this article openly available.

Please share how this access benefits you. Submit a story.

\section{Accessibility}




\section{CHICAGO JOURNALS}

\section{The Embodiment Hypothesis}

Author(s): Dale W. Jorgenson

Source: The Journal of Political Economy, Vol. 74, No. 1 (Feb., 1966), pp. 1-17

Published by: The University of Chicago Press

Stable URL: http://www.jstor.org/stable/1829196

Accessed: 07 $/ 11 / 2009$ 12:39

Your use of the JSTOR archive indicates your acceptance of JSTOR's Terms and Conditions of Use, available at http://www.jstor.org/page/info/about/policies/terms.jsp. JSTOR's Terms and Conditions of Use provides, in part, that unless you have obtained prior permission, you may not download an entire issue of a journal or multiple copies of articles, and you may use content in the JSTOR archive only for your personal, non-commercial use.

Please contact the publisher regarding any further use of this work. Publisher contact information may be obtained at http://www.jstor.org/action/showPublisher?publisherCode=ucpress.

Each copy of any part of a JSTOR transmission must contain the same copyright notice that appears on the screen or printed page of such transmission.

JSTOR is a not-for-profit service that helps scholars, researchers, and students discover, use, and build upon a wide range of content in a trusted digital archive. We use information technology and tools to increase productivity and facilitate new forms of scholarship. For more information about JSTOR, please contact support@jstor.org. 


\section{THE JOURNAL OF \\ POLITICAL ECONOMY \\ Volume LXXIV \\ FEBRUARY 1966 \\ Number I}

\section{THE EMBODIMENT HYPOTHESIS}

DALE W. JORGENSON

University of California, Berkeley

\section{INTRODUCTION}

I $\mathrm{N}$ THE study of total factor productivity two distinct approaches have been employed. First, total factor productivity may be treated as an index number, the ratio of indexes of total output and total input. Since the rates of growth of output and input vary from period to period, the rate of growth of total factor productivity may vary. Second, total factor productivity may be treated as a function of a particular form, for example, an exponential function of time. The parameters of such a function may be treated as unknowns to be estimated from data on output and input. Where total factor productivity grows exponentially, the rate of growth remains constant.

In either approach changes in the index of total factor productivity may be interpreted as shifts in an aggregate production function or as "disembodied" technical change. This interpretation of an index of total factor productivity with a constant rate of growth was first proposed by Tinbergen (1959, pp. 190-95). The corresponding interpretation of total factor productivity with a rate of growth that varies was first given by Solow (1957, pp. 312-13). More recently, changes in the index of total factor productivity have been interpreted by Solow as technical change "embodied" in new capital goods (1960, p. 91). Solow assumes that embodied technical change takes place at a constant exponential rate, but it is clear that the rate of growth could be treated as varying from period to period. Solow also assumes, implicitly, that consumption goods and investment goods as conventionally measured are perfect substitutes in production. The first objective of this paper is to provide a model of embodied technical change free of these two restrictive assumptions.

It has frequently been suggested that embodied and disembodied technical change are two different aspects of reality. For example, in commenting on Denison's study of total factor productivity (1962), based on disembodied technical change, Abramovitz says: "The economic model which underlies Denison's calculations stands in sharp contrast to the model with which Robert 
Solow has been experimenting. ... The factual gap between the two views is profound and not really usefully attacked by speculation" (1962, p. 773).

Denison takes Abramovitz to task for stressing the importance of the question of embodiment, suggesting that "the whole embodiment question is of little importance for policy in the United States" (1964, p. 90). However, Denison does not dispute Abramovitz' basic presupposition that embodied and disembodied technical change may be distinguished by an appeal to evidence. The second objective of this paper is to examine this presupposition. After dropping the highly restrictive assumption that technical change proceeds at constant exponential rates, we are able to show that one can never distinguish a model of embodied technical change from a model of disembodied technical change on the basis of factual evidence such as that considered by Denison and Solow. Both types of technical change have precisely the same factual implications so that the "factual gap" suggested by Abramovitz is entirely illusory.

The conclusion that embodied and disembodied technical change have the same factual implications has importance for economic policy. In measuring potential economic growth it is often useful to calculate the amount of investment required for a given amount of economic growth. Calculations based on models of disembodied and embodied technical change give startlingly different results. Although differences in the results are often attributed to differences in the underlying models, the precise equivalence between the two models reveals that the source of the difference lies not in the models but, rather, in different assumptions about the facts. To illustrate: One can calculate the effects of investment for a model with a given rate of disembodied technical change. Using the correspondence between models of embodied and disembodied technical change, one can calculate the effects of investment for a model with the corresponding rate of growth of embodied technical change. The results for the two models will agree perfectly. On the other hand, one can do the second calculation for a model with a different rate of embodied technical change. Obviously, the results of the two calculations will differ. The difference in the results can be attributed to the fact that different assumptions are made concerning the rate of embodied technical change. In weighing the implications of calculations that differ, the problem is not to choose the correct model but rather to choose the correct factual assumption.

\section{THEORY}

We first consider the simplest theoretical framework which encompasses both embodied and disembodied technical change. Within this framework we are able to eliminate the restrictive assumptions that consumption goods and investment goods are perfect substitutes in production and that technical change proceeds at constant exponential rates. To present the theoretical framework we let $C$ and $I$ represent the quantities of consumption and investment goods, $K$ and $L$ the quantities of capital and labor services, $q_{C}$ and $q_{I}$ the prices of consumption and investment goods, and $p_{K}$ and $p_{L}$ the prices of capital and labor services. The fundamental identity for each accounting period is that value of output is equal to value of input:

$$
q_{C} C+q_{I} I=p_{K} K+p_{L} L .
$$

This accounting identity is important in defining total factor productivity.

To define total factor productivity we 
first differentiate the fundamental identity (1) with respect to time and divide both sides by total value. (Time derivatives of variables are denoted by primes.) The result is an identity between weighted averages of rates of growth of output prices and quantities and rates of growth of input prices and quantities:

$$
\begin{aligned}
& v_{C}\left(\frac{q_{C}^{\prime}}{q_{C}}+\frac{C^{\prime}}{C}\right)+v_{I}\left(\frac{q_{I}^{\prime}}{q_{I}}+\frac{I^{\prime}}{I}\right) \\
& =w_{K}\left(\frac{p_{K}^{\prime}}{p_{K}}+\frac{K^{\prime}}{K}\right)+w_{L}\left(\frac{p_{L}^{\prime}}{p_{L}}+\frac{L^{\prime}}{L}\right) .
\end{aligned}
$$

The weights $v_{C}, v_{I}$ and $w_{K}, w_{L}$ are relative value shares:

$$
\begin{aligned}
v_{C} & =\frac{q_{C} C}{q_{C} C+q_{I} I}, & v_{I} & =\frac{q_{I} I}{q_{C} C+q_{I} I} ; \\
w_{K} & =\frac{p_{K} K}{p_{K} K+p_{L} L}, & w_{L} & =\frac{p_{L} L}{p_{K} K+p_{L} L} .
\end{aligned}
$$

To verify that both sides of the identity (2) are weighted averages, we observe that:

$$
\begin{gathered}
v_{C}, v_{I} \geq 0, \quad w_{K}, w_{L} \geq 0 ; \\
v_{C}+v_{I}=w_{K}+w_{L}=1 .
\end{gathered}
$$

A useful index of total output is provided by the weighted average of rates of growth of output from (2); denoting this index of output by $Y$ :

$$
\frac{Y^{\prime}}{Y}=v_{C} \frac{C^{\prime}}{C}+v_{I} \frac{I^{\prime}}{I}
$$

an analogous index of the quantity of total input, say $X$, is:

$$
\frac{X^{\prime}}{X}=w_{K} \frac{K^{\prime}}{K}+w_{L} \frac{L^{\prime}}{L} .
$$

These quantity indexes are familiar as Divisia quantity indexes. In terms of Divisia index numbers a natural definition of total factor productivity, say $P$, is the ratio of the quantity of total output to the quantity of total input:

$$
P=\frac{Y}{X} \text {. }
$$

Using the definitions of Divisia quantity indexes, the rate of growth of total factor productivity may be expressed as: ${ }^{1}$

$$
\begin{aligned}
\frac{P^{\prime}}{P}=\frac{Y^{\prime}}{Y}-\frac{X^{\prime}}{X}=v_{C} & \frac{C^{\prime}}{C}+v_{I} \frac{I^{\prime}}{I} \\
& -w_{K} \frac{K^{\prime}}{K}-w_{L} \frac{L^{\prime}}{L} .
\end{aligned}
$$

1 These index numbers were first proposed by Divisia in 1925 (1925; 1926; 1928). Somewhat more accessible discussions of Divisia's work may be found in Frisch's survey article on the theory of index numbers (1936) and in Wold's book on demand analysis (1953). In a more recent publication, Divisia suggests the application of these indexes to the measurement of total factor productivity (1952, pp. 53-54). Even more recently, Solow has given an explicit derivation of the Divisia quantity index of total factor productivity (1957, p. 312) and has applied this index to data for the U.S. private nonfarm economy, 1909-49.

The Divisia price indexes for total output and total input, say $q$ and $p$, are:

$$
\begin{aligned}
& \frac{q^{\prime}}{q}=w_{C} \frac{q_{C}^{\prime}}{q_{C}}+w_{I} \frac{q_{I}^{\prime}}{q_{I}}, \\
& \frac{p^{\prime}}{p}=v_{K} \frac{p_{K}^{\prime}}{p_{K}}+v_{L} \frac{p_{L}^{\prime}}{p_{L}},
\end{aligned}
$$

respectively. An alternative definition of total factor productivity, which may be somewhat less familiar than expression (3) given in the text, is the ratio of the price of a unit of input to the price of a unit of output: $P=p / q$.

Using the definitions of Divisia price indexes, $p$ and $q$, the rate of growth of total factor productivity may be expressed as:

$$
\frac{p^{\prime}}{P}=w_{K} \frac{p_{K}^{\prime}}{p_{K}}+w_{L} \frac{p_{L}^{\prime}}{p_{L}}-v_{C} \frac{q_{C}^{\prime}}{q_{C}}-v_{I} \frac{q_{I}^{\prime}}{q_{I}},
$$

which corresponds to expression (4) of the text. These two expressions for the rate of growth of total factor productivity are dual to each other; by itself each provides a complete definition of total factor productivity; the two definitions are equivalent by the identity (2).

Any index of total factor productivity may be computed either from quantity indexes of total out- 
Divisia index numbers have the fundamental reproductive property, namely, a Divisia index of a group of Divisia indexes is also a Divisia index of the components of each group. This property assures us that no distinction need be made between a one-sector model with joint production of consumption and investment goods and a two-sector model with one sector corresponding to each output, ${ }^{2}$

put and total input or from the corresponding price indexes. The whole analysis that follows could be carried out in an entirely equivalent way, using price indexes instead of quantity indexes.

For present purposes we do not consider explicitly other explanations of change in total factor productivity, such as economies of scale, external economies, or economic disequilibrium. In both embodiment and disembodiment explanations of change in total factor productivity, these additional explanatory factors can be lumped together with pure technical change or treated separately. To simplify the following discussion, such factors will not be distinguished from technical change.

${ }^{2}$ The analysis of total factor productivity can be carried out equivalently through index-number formulas or through production functions. From a purely formal point of view, both index-number formulas and production functions may be interpreted as mean value functions (Hardy, Littlewood, and Polya, 1952, pp. 12-14). Production functions have been discussed from this point of view by Arrow, Chenery, Minhas, and Solow (1961, pp. 23031 ), while index-number formulas have been discussed from the same point of view by Wold (1953, pp. 132-39, esp. p. 133).

Tinbergen (1959, pp. 190-95) interprets the geometric quantity index of total factor productivity as a Cobb-Douglas production function. As further examples of index-number formulas that have been interpreted as production functions, a fixed-weight Laspeyres quantity index of total factor productivity may be interpreted as a "linear" production function, that is, as a production function with infinite elasticity of substitution, as Solow (1957, p. 317) and Clemhout (1963, pp. 358-60) have pointed out. In a sense, output-capital or output-labor ratios correspond to Leontief-type production functions, that is, to production functions with zero elasticity of substitution, as Domar points out (1961, p. 712-13).

To date, no attempt has been made to utilize the index-number formula which may be interpreted as a production function with arbitrary elasticity of substitution; of course, all the index-number formulas we have mentioned are special cases or limiting cases of such a formula. provided that the index of total output is a Divisia index of the outputs of the two sectors and the index of total inputs is a Divisia index of the inputs of the two sectors. If the price of an input is the same in both sectors, the appropriate index for this input may be constructed either as a Divisia index of the amounts of this input or as an ordinary sum of the amounts of the input. ${ }^{3}$

\section{MEASUREMENT}

Conceptually, the measurement of output and labor services is straightforward. Beginning with data on the value of transactions in each output and labor service, the value is separated into price and a quantity. A quantity index may be constructed from the individual quantities, using relative value shares as weights.

If capital services were supplied and employed by distinct economic units, there would be no conceptual difference between construction of indexes for capital input and for labor input. Beginning with data on the value of transactions in each capital service, the value would be separated into a price and a quantity. A quantity index for capital input would be constructed from the quantities of each capital service, using as weights the relative value shares, that is, the shares of each capital service in the rental value of all capital services.

Measurement of capital services is less straightforward than measurement of labor services because the employer of a capital service is usually also the supplier of the service. Data on values of transactions in capital services are recorded only in the internal accounts of economic units. To extract the required informa-

${ }^{3}$ This condition corresponds to Hicks's condition for aggregation of commodities in demand analysis (1946, pp. 312-13). Wold (1953, p. 109) calls this result the Leontief-Hicks Theorem. 
tion it is necessary to begin not with transactions in capital services but with transactions in investment goods. These values must first be separated into a price and a quantity. Second, the quantity of new investment goods reduced by the quantity of investment goods replaced must be added to accumulated stocks. Finally, the price and quantity of capital services for each stock must be calculated.

Calculation of an index of capital input from data on transactions in new investment goods depends on hypotheses about the rate of replacement of investment goods and about the quantity of capital services corresponding to a given capital stock. In this paper we assume that capital services are proportional to the $\mathrm{cu}$ mulated stock of past investments. Second, we assume that the proportion of an investment replaced in an interval of time declines exponentially over time. ${ }^{4}$ Under this assumption the cumulated stock of past investments, net of replacements, satisfies the well-known relationship:

$$
I=K^{\prime}+\delta K,
$$

where $\delta$ is the instantaneous rate of replacement of investment goods.

Before considering alternative explanations of change in total factor productivity, we must discuss the effects of errors of measurement in the separation of transaction values into prices and quantities. Direct observations are usually

${ }^{4} \mathrm{~A}$ theoretical justification for this assumption is that replacement of investment goods is a recurrent event. An initial investment generates an infinite series of replacement investments over time. The distribution of replacements for such an infinite stream approaches a constant fraction of the accumulated stock of investment goods for any "survival curve" of individual pieces of equipment; but this is precisely the relationship between replacement and accumulated stock if an exponentially declining proportion of any given investment is replaced in a given interval of time, available only for the values; the separation of these values into prices and quantities is based on much less complete information. It is important to consider the effects of systematic errors in this separation.

For consumption goods or labor services an error in separating the value of transactions into prices and quantities results in errors in the price and quantity of total output or total input. Errors in total output or input result in errors in total factor productivity. As an example, suppose that the price of a labor service is measured with error. Since all relative value shares are given data, the rate of growth of the error in the price of total input is equal to that of the error in the price of the labor service, multiplied by the relative value share of the service. The quantity of total input is measured with an error that is equal in magnitude but opposite in sign. The error in the rate of growth of total factor productivity is equal to the negative of the rate of growth of the error in total input. The effects of an error in the rate of growth of the price of consumer goods are entirely analogous; of course, an upward bias in the rate of growth of output increases the measured rate of growth of total factor productivity, while an upward bias in the rate of growth of input decreases the measured rate of growth.

Measurement of capital input is based, ultimately, on the separation of the value of transactions in new investment goods into a price and a quantity. An error in this separation will affect the measured prices and quantities of investment goods and capital services, and also measured total factor productivity. To examine these effects we let $Q$ represeint the relative error in the price of investment goods and $I^{*}$ the "quantity" of investment goods calculated using the errone- 
ous price. The bias in the rate of growth of investment goods output is then:

$$
\frac{I^{*}}{I^{*}}-\frac{I^{\prime}}{I}=-\frac{Q^{\prime}}{Q} \text {. }
$$

The rate of growth of this bias is negative if the rate of growth of the error is positive, and vice versa. If we let $K^{*}$ be the "quantity" of capital calculated using the erroneous price:

$$
\begin{aligned}
K^{*}=\int_{-\infty}^{t} e^{-\delta(t-s)} I^{*}(s) d s \\
=\int_{-\infty}^{t} e^{-\delta(t-s)} \frac{I(s)}{Q(s)} d s .
\end{aligned}
$$

The bias in the rate of growth of the quantity of capital services is then:

$$
\begin{aligned}
\frac{K^{*}}{K^{*}}-\frac{K^{\prime}}{K}= & \frac{I}{Q K^{*}}-\frac{I}{K} \\
= & \frac{I}{\int_{-\infty}^{t} e^{-\delta(t-s)} \frac{Q(t)}{Q(s)} I(s) d s} \\
& -\frac{I}{\int_{-\infty}^{t} e^{-\delta(t-s)} I(s) d s} .
\end{aligned}
$$

The bias is negative if the rate of growth of the error is positive, and vice versa.

To calculate the error of measurement in total factor productivity, we represent the rate of growth of total factor productivity as before:

$$
\frac{P^{\prime}}{P}=v_{I} \frac{I^{\prime}}{I}+v_{C} \frac{C^{\prime}}{C}-w_{K} \frac{K^{\prime}}{K}-w_{L} \frac{L^{\prime}}{L} .
$$

If we let $P^{*}$ represent measured total factor productivity using the erroneous price of investment goods:

$$
\frac{P^{* *}}{P^{*}}=v_{I} \frac{I^{\prime *}}{I^{*}}+v_{C} \frac{C^{\prime}}{C}-w_{K} \frac{K^{*}}{K^{*}}-w_{L} \frac{L^{\prime}}{L} .
$$

Subtracting the first of these expressions from the second, we obtain the bias in the rate of growth of total factor productivity:

$$
\begin{aligned}
\frac{P^{*}}{P^{*}}-\frac{P^{\prime}}{P}=v_{I}\left(\frac{I^{*}}{I^{*}}-\frac{I^{\prime}}{I}\right) & \\
& -w_{K}\left(\frac{K^{*}}{K^{*}}-\frac{K^{\prime}}{K}\right) .
\end{aligned}
$$

Substituting expressions (7) and (6) for the biases in capital input and investment goods output, we have:

$$
\begin{aligned}
\frac{P^{*}}{P^{*}}-\frac{P^{\prime}}{P} & =-v_{I} \frac{Q^{\prime}}{Q} \\
-w_{K}\left[\frac{I}{\int_{-\infty}^{t} e^{-\delta(t-s)} \frac{Q(t)}{Q(s)} I(s) d s}\right. & \left.-\frac{I}{\int_{-\infty}^{t} e^{-\delta(t-s)} I(s) d s}\right] .
\end{aligned}
$$

In investment and the error are growing at constant rates, the biases in the rates of growth of the quantity of investment goods produced and the quantity of capital services are equal; the net effect is equal to the rate of growth of the error, multiplied by the difference between the capital share in total input and the investment share in total output. ${ }^{5}$

We conclude that so long as the capital share is greater than the investment share and the investment share is not zero, one can produce any rate of growth in measured total factor productivity by introducing a sufficiently large error in the measured rate of growth of the price of investment goods. This conclusion is entirely independent of whether actual total factor productivity is changing or not. To be more specific, if the capital share in total input is greater than the investment share in total output, a posi-

${ }^{5}$ This result does not agree with Domar's result on a closely related problem (1963, p. 587 , formula [5]), because Domar assumes that capital input into the production of investment goods "is imported from the outside." Using the condition that capital input commands the same rental value in both sectors, the need for this specialization may be eliminated as previously indicated in text. The correct result for the general case is that given in the text. 
tive rate of growth in total factor productivity can be produced by introducing an error in measurement of the price of investment goods with a positive rate of growth. The converse of this proposition is that one may reduce the rate of growth in measured total factor productivity by introducing a bias in the opposite direction in the measured rate of growth of the price of investment goods. In particular, one can eliminate growth in total factor productivity altogether by suitably "adjusting" the measured price of investment goods. ${ }^{6}$ An explicit formula for the "adjustment" is obtained by setting the bias in the rate of growth of total factor productivity in (8) equal to the negative of the actual rate of growth, that is, by setting the erroneously measured rate of growth, $P^{\prime *} / P^{*}$, equal to zero. This results in the following relationship between total factor productivity, $P$, and the relative error in the measurement of the price of investment goods, $Q$ :

$$
\begin{aligned}
\frac{P^{\prime}}{P} & =v_{I} \frac{Q^{\prime}}{Q} \\
+w_{K} & {\left[\frac{I}{\int_{-\infty}^{t} e^{-\delta(t-s)} \frac{Q(t)}{Q(s)} I(s) d s}\right.} \\
& \left.-\frac{I}{\int_{-\infty}^{t} e^{-\delta(t-s)} I(s) d s}\right] .
\end{aligned}
$$

${ }^{6}$ This appears to be what Denison has in mind in stating that: "The frequently advanced proposition that inputs should be measured in units of constant quality, as determined by their ability to contribute to production is tantamount to making the index of [total input] identical with that of [total output]" (1961, pp. 349-50). For example, it is always possible to "adjust" the price of investment goods so that total factor productivity is constant. However, Denison's conclusion is false in general; not every adjustment for quality change will eliminate total factor productivity. Whether a particular adjustment will have this effect is generally a refutable proposition and can be tested quite simply by appealing to the evidence. However, every adjustment computed from a formula like (9), in text, will eliminate total factor productivity; this is true by definition and is not refutable by any appeal to the evidence.
The relationship (9) between total factor productivity, $P$, and the relative error in the measurement of investment goods, $Q$, may be interpreted in two ways. First, suppose that we have a relative error for which the measured rate of growth of total factor productivity is zero. Then, we may calculate the actual rate of growth of total factor productivity, $P^{\prime} / P$, by treating the right-hand side of expression (9) as a given function of time. Alternatively, suppose that we have actual total factor productivity, $P$; then we may calculate the rate of growth of the corresponding relative error in the measurement of the price of investment goods, $Q^{\prime} / Q$, by treating the left-hand side of expression (9) as a given function of time.

Our principal conclusion is that there is a one-to-one correspondence between indexes of total factor productivity, $P$, and errors in the price of investment goods, $Q$, that can make the rate of growth in measured total factor productivity equal to zero. ${ }^{7}$ In view of this correspondence one can never distinguish a given rate of growth in total factor productivity from the corresponding rate of

${ }^{7}$ See the Mathematical Appendix. More precisely, we may say that the definition of each index generates a two-parameter family of indexes. The parameters that generate a given member of each family may be interpreted as initial values of the index of technical change and the corresponding index of capital stock. For a given set of data any pair of indexes consisting of one member of each of the families satisfies expression (9). There is a oneto-one correspondence between the families of indexes constructed from a given set of data. In this paper we leave open the question of whether disembodied technical change is an explanation of change in total factor productivity or simply a relabeling of Our Ignorance, as some have suggested. For those who prefer to call disembodied technical change a relabeling of Our Ignorance, expression (9) says that the relative error in the price of investment goods is an alternative and entirely equivalent relabeling of Our Ignorance. This is certainly a valid interpretation of the relative error in the price of investment goods. An alternative interpretation of the error is suggested below. 
growth in the error in measurement of the price of investment goods. Given any observed index of total factor productivity, one can always relabel it as an error in the measurement of the price of investment goods. This relabeling is irrefutable on the basis of the data that underlie expressions (8) and (9) because the whole procedure is purely definitional. It amounts to computing two completely interchangeable quantities, $P$ and $Q$, and giving each a different name.

\section{EXPLANATION}

Up to this point we have interpreted expression (8) as a relationship between the relative error in the measurement of total factor productivity, $P^{*} / P$, and the relative error in the measurement of the price of investment goods, $Q$. Suppose we set the erroneously measured index of total factor productivity, $P^{*}$, equal to unity, so that the rate of growth of this index is zero. Then expression (9) becomes a relationship between the relative error in the measurement of the price of investment goods, $Q$, and total factor productivity.

Expression (8) has another interesting interpretation. We may interpret the rate of growth of total factor productivity, $P$, as the rate of disembodied technical change. Second, we may interpret the reciprocal of the relative error in the price of investment goods, $1 / Q$, as an index of the quality of investment goods. The rate of growth of this index may be interpreted as the rate of embodied technical change. In this interpretation, the "erroneously" measured quantities of investment goods output, $I^{*}$, and capital input, $K^{*}$, are "surrogate" investment and "surrogate" capital, that is, investment and capital corrected for quality change.

We may interpret expression (9) as a relationship between the rate of disem- bodied technical change and the rate of embodied technical change. For any index of embodied technical change, we may calculate the corresponding index of disembodied technical change by treating the right-hand side of expression (9) as a given function of time. Alternatively, for any index of disembodied technical change, we may calculate the corresponding index of embodied technical change by treating the left-hand side of expression (9) as a given function of time. As before, we conclude that there is a one-to-one correspondence between indexes of embodied technical change and indexes of disembodied technical change. In view of this correspondence one can never distinguish a given rate of growth in embodied technical change from the corresponding rate of growth in disembodied technical change.

We conclude that one can always relabel any observed rate of growth in the index of disembodied technical change as a corresponding rate of growth in the index of embodied technical change. This relabeling is irrefutable on the basis of the data that underlie expressions (8) and (9) because the two indexes, $P$ and $1 / Q$, are completely interchangeable by means of expression (9). Any set of facts may be interpreted equivalently as embodied or disembodied technical change.

To illustrate the fact that any index of disembodied technical change, $P$, is completely interchangeable with an index of embodied technical change, $1 / Q$, we compute an index of each type for the U.S. private domestic economy, 1939-59. The data given at the outset include time series on prices and quantities of investment-goods output, consumption-goods output, and labor input, and the rate of replacement of capital goods. From these data the relative value shares of investment goods, consumption goods, capital services, and labor services, together with 
rates of growth of each of the output and input quantities, may be computed. The derived value shares and rates of growth for the U.S. private domestic economy are presented in Table $1 .^{8}$

Indexes of disembodied and embodied technical change for the U.S. private domestic economy are presented in Table $2 .{ }^{9}$ Although the calculated indexes are meant to illustrate the equivalence of studies. ${ }^{10}$ On the other hand, the average rate of growth of the index of embodied technical change is 0.101 ; this value may be compared with the experimental values of 0.01 and 0.05 employed by Solow. ${ }^{11}$

The conceptualization of embodied technical change that underlies expressions (6) and (7) above is not the only possible conceptualization. Solow has based his calculations on the assumption

TABLE 1

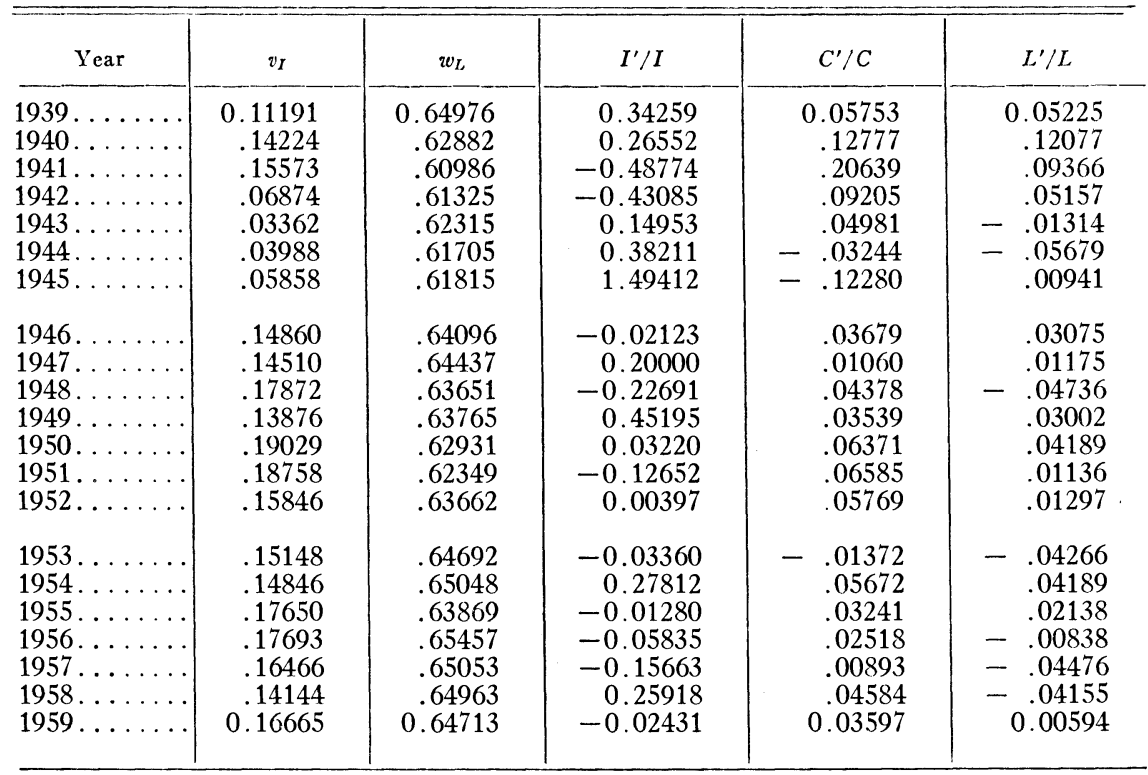

embodied and disembodied technical change, perhaps a comment on the empirical results is not entirely out of order. The average rate of growth of the index of disembodied technical change is approximately 0.024 , which is roughly comparable with the results of previous

${ }^{8}$ These data are based on those of Kendrick (1961; Kendrick and Sato, 1963, pp. 996-1002). For the period 1939-59 Kendrick's data on the output of consumption and investment goods are based on the Office of Business Economics accounts for gross national product. In all of the calculations given in Table 2, the rate of replacement is assumed to be 0.025 .

${ }^{9}$ For details of the method of calculation, consult the Mathematical Appendix. that consumption goods and investment goods as conventionally measured are perfect substitutes in production. This assumption implies that for investment goods of a fixed vintage, the output of consumption goods attainable from given quantities of capital and labor is the same at any point in time. However, for

${ }^{10} \mathrm{~A}$ comparison of the principal alternative estimates is provided by Abramovitz (1962, p. 765).

11 This empirical result may explain the seeming anomaly that the goodness of fit of a production function based on embodied technical change increases throughout the range of values considered by Solow. Further light is thrown on this question by the index of embodied technical change presented in Table 4 below. 
these same investment goods of fixed vintage the output of investment goods of a particular quality attainable from a given quantity of capital and labor varies over time. In effect, Solow assumes that investment goods of a given vintage progress technologically over time but only in the production of investment goods. In a two-sector model Solow's assumption would be equivalent to the assumption
Solow adjusts the quantity of capital for quality change. He calls the resulting quantity of capital, $K^{*}$ in our notation, a "surrogate" quantity of capital. To avoid the implication that disembodied technical change occurs for investment goods of a given vintage, at least in the production of new investment goods, it is necessary to adjust the quantity of investment goods produced as well. The

TABLE 2

\begin{tabular}{|c|c|c|c|c|}
\hline Year & $P^{\prime} / P$ & $-Q^{\prime} / Q$ & $P$ & $1 / Q$ \\
\hline $\begin{array}{l}1939 \ldots \ldots \\
1940 \ldots \ldots \\
1941 \ldots \ldots \\
1942 \ldots \ldots \\
1943 \ldots \ldots \\
1944 \ldots \ldots \\
1945 \ldots \ldots\end{array}$ & $\begin{array}{r}0.05379 \\
.06589 \\
.03143 \\
.02474 \\
.06555 \\
.02255 \\
-.03288\end{array}$ & $\begin{array}{r}-0.23195 \\
-0.27984 \\
-0.05397 \\
-0.14844 \\
-0.97679 \\
-0.54131 \\
1.01487\end{array}$ & $\begin{array}{l}0.68852 \\
0.72556 \\
0.77337 \\
0.79768 \\
0.81741 \\
0.87099 \\
0.89063\end{array}$ & $\begin{array}{l}2.32783 \\
1.78789 \\
1.28757 \\
1.21808 \\
1.03727^{*} \\
0.86328^{*} \\
0.71848^{*}\end{array}$ \\
\hline $\begin{array}{l}1946 \ldots \ldots \\
1947 \ldots \ldots \\
1948 \ldots \ldots \\
1949 \ldots \ldots \\
1950 \ldots \ldots \\
1951 \ldots \ldots \\
1952 \ldots \ldots\end{array}$ & $\begin{array}{r}.00260 \\
.02060 \\
.01209 \\
.06658 \\
.01640 \\
.00768 \\
.03041\end{array}$ & $\begin{array}{r}0.11596 \\
-0.02590 \\
0.04376 \\
-0.28358 \\
0.16137 \\
0.22434 \\
0.12228\end{array}$ & $\begin{array}{l}0.86135 \\
0.85911 \\
0.87681 \\
0.88741 \\
0.94649 \\
0.96201 \\
0.96940\end{array}$ & $\begin{array}{l}0.59797 \\
0.66731 \\
0.65003 \\
0.67848 \\
0.48608 \\
0.56452 \\
0.69116\end{array}$ \\
\hline $\begin{array}{l}1953 \ldots \ldots \\
1954 \ldots \ldots \\
1955 \ldots \ldots \\
1956 \ldots \ldots \\
1957 \ldots \ldots \\
1958 \ldots \ldots \\
1959 \ldots \ldots\end{array}$ & $\begin{array}{r}.00112 \\
.05382 \\
.00195 \\
.00421 \\
.00088 \\
.04265 \\
0.01186\end{array}$ & $\begin{array}{r}0.28920 \\
-0.00616 \\
0.37577 \\
0.42195 \\
0.54246 \\
0.45309 \\
0.90646\end{array}$ & $\begin{array}{l}0.99888 \\
1.00000 \\
1.05382 \\
1.05587 \\
1.06032 \\
1.06125 \\
1.10651\end{array}$ & $\begin{array}{l}0.77567 \\
1.00000 \\
0.99384 \\
1.36730 \\
1.94422 \\
2.99887 \\
4.35761\end{array}$ \\
\hline
\end{tabular}

* Calculated from $-Q^{\prime} / Q$ by averaging values for 1943-45.

that all technical change is of the disembodied variety but that technical change is confined to the investment-goods sector. ${ }^{12}$ The further assumption that investment goods and consumption goods are perfect substitutes in production implies that the production functions in the two sectors are identical.

12 Solow points out that: "This [rate of gross investment] is not a wholly unambiguous notion. By the same rate of gross investment I mean the same physical output of 'machines.' But machines behave differently in the two economies [with embodied and disembodied technical change] and so must asset valuation. Production of identical numbers of machines may have quite different implications in value terms" (1960, p. 93, n. 5). resulting quantity of investment goods, $I^{*}$ in our notation, would then be an appropriate "surrogate" quantity of investment goods. In the absence of this second adjustment, expression (9) reduces to:

$$
\begin{array}{r}
\frac{P^{\prime}}{P}=w_{K}\left[\frac{I}{\int_{-\infty}^{t} e^{-\delta(t-s)} \frac{Q(t)}{Q(s)} I(s) d s}\right. \\
\left.-\frac{I}{\int_{-\infty}^{t} e^{-\delta(t-s)} I(s) d s}\right],
\end{array}
$$

which corresponds to formula (12) in Solow's first article on embodied technical change (1960, p. 94). 
Expression (10) may be interpreted in the same way as formula (9). Given the index of the quality of investment goods, the corresponding index of disembodied technical change may be calculated by treating the right-hand side of expression (10) as a given function of time. Alternatively, for a given index of disembodied technical change, the rate of growth of the index of embodied technical change may be calculated by treating the lefthand side of expression (10) as a given function of time. As before, there is a one-to-one correspondence between indexes of embodied and disembodied technical change. In view of this correspondence one can never distinguish a given rate of growth in embodied technical change from the corresponding rate of growth in disembodied technical change.

We conclude that one can always relabel any observed rate of growth in the index of disembodied technical change as a corresponding rate of growth in the index of embodied technical change calculated on Solow's assumptions. This relabeling is irrefutable on the basis of the data that underlie expression (10), because the two indexes are completely interchangeable by means of this expression. To illustrate the fact that any index of disembodied technical change is completely interchangeable with an index of embodied technical change calculated on Solow's assumptions, an appropriate index of embodied technical change is presented for the U.S. private domestic economy, 1939-59, in the first column of Table 3.

Solow's assumption that consumption goods and investment goods as conventionally measured are perfect substitutes in production has at least one readily testable implication. This implication is that so long as both consumption goods and investment goods are produced in positive amounts, the prices of the two goods must be proportional to each other. In the present context this implies that the implicit deflators of consumption and investment goods must be proportional or that the rates of growth of these defiators must be equal. A careful and thoroughly documented test of this hypothesis has been carried out by R. A. Gordon

TABLE 3

\begin{tabular}{|c|c|c|c|}
\hline Year & $-Q^{\prime} / Q$ & $q_{c}^{\prime} / q_{C}$ & $q_{I}^{\prime} / q_{I}$ \\
\hline $\begin{array}{l}1939 \ldots \\
1940 \ldots \\
1941 \ldots \\
1942 \ldots \\
1943 \ldots \\
1944 \ldots \\
1945 \ldots\end{array}$ & $\begin{array}{r}-0.00796 \\
-0.50671 \\
0.26828 \\
1.58115 \\
-0.59978 \\
-2.17661 \\
-3.40897\end{array}$ & $\begin{array}{r}0.01542 \\
.09511 \\
.13184 \\
.10196 \\
.01568 \\
.00915 \\
.09664\end{array}$ & $\begin{array}{r}0.05255 \\
.08554 \\
.06669 \\
-.00362 \\
.10759 \\
.05840 \\
.08174\end{array}$ \\
\hline $\begin{array}{l}1946 \ldots \\
1947 \ldots \\
1948 \ldots \\
1949 \ldots \\
1950 \ldots \\
1951 \ldots \\
1952 \ldots\end{array}$ & $\begin{array}{r}0.73106 \\
-0.26175 \\
1.69931 \\
-0.79225 \\
0.99485 \\
-0.02812 \\
-0.46928\end{array}$ & $\begin{array}{r}.10877 \\
.05709 \\
-.00960 \\
.00330 \\
.07874 \\
.01828 \\
.00678\end{array}$ & $\begin{array}{r}.14219 \\
.14135 \\
-.01000 \\
.04363 \\
.09219 \\
.01334 \\
.00558\end{array}$ \\
\hline $\begin{array}{l}1953 \ldots \\
1954 \ldots \\
1955 \ldots \\
1956 \ldots \\
1957 \ldots \\
1958 \ldots \\
1959 \ldots\end{array}$ & $\begin{array}{r}2.68494 \\
-0.80062 \\
0.10595 \\
-0.13054 \\
2.14949 \\
-0.59412 \\
-0.14750\end{array}$ & $\begin{array}{r}.00796 \\
.00558 \\
.01906 \\
.04410 \\
.01591 \\
.01134 \\
0.01196\end{array}$ & $\begin{array}{r}.00459 \\
.02215 \\
.06878 \\
.04240 \\
.01565 \\
.01969 \\
0.01126\end{array}$ \\
\hline
\end{tabular}

(1961). Gordon's conclusions may be quoted in full:

There has apparently been, for half a century or more, a secular tendency in the United States and some other countries for capital-goods prices to rise faster than those of consumers' goods.

If we can believe the figures, the contrast in the behavior of these sector price levels has been quite striking, particularly for the period since the 1920's. The contrast also shows up in earlier decades in the U.S. figures. The tendency for capital-goods prices to rise faster than those of consumers' goods is not confined to the United States. It is also evidenced in some, although not all, other advanced countries for which data are available [1961, p. 937].

The rates of growth of implicit deflators for consumption and investment goods for the U.S. private domestic econ- 
omy, 1939-59, are presented in Table 3. In this table $q_{C}^{\prime} / q_{C}$ is the rate of growth of the implicit deflator for consumption goods, and $q_{I}^{\prime} / q_{I}$ is the rate of growth of the implicit deflator for investment goods. The hypothesis that the rates of growth are equal may be rejected, but only at a .25 level of significance. We conclude that the assumption that consumption goods and investment goods as conventionally measured are perfect substitutes in production is inconsistent with the evidence presented by Gordon and also weakly inconsistent with evidence for the U.S. private domestic economy, 1939-59. The index of embodied technical change presented in the second column of Table 2, unlike that given in the first column of Table 3 , does not require this assumption.

\section{PREDICTION}

We turn now to consideration of calculations of the amount of investment required to attain a given amount of economic growth. Many such calculations have been made and published; the results may be summarized, again in the words of Abramovitz: "It is an implication of Denison's analysis that we might do much to stimulate growth without raising our investment quotas. We might even permit them to sink, but in order to stimulate growth significantly through capital accumulation we should have to increase our investment quotas enormously. The moral of Solow's view is just the opposite. Pressed to the limit, nothing we might do to stimulate growth would be effective without a good deal of investment" (1962, p. 779).

Since embodied and disembodied technical change have the same factual implications, any statement based on one type of technical change can be translated into an entirely equivalent statement based on the other type of technical change.
Expression (9) provides a means of making such translations. If the results of calculations based on embodied technical change differ from those based on disembodied technical change, the reason must be that the two statements, translated into the same framework, involve not two different models of technical change but, rather, two different factual assumptions within a given model of technical change. No one would knowingly deny that calculations based on a rate of disembodied technical change of, say, 4 per cent per year will give different results than calculations based on a rate of 5 per cent per year. However, it is easy to deny such a proposition inadvertently. One could calculate the effects of investment for a disembodied model with a rate of disembodied technical change of 4 per cent per year and then calculate the effects of investment for an embodied model with a rate of disembodied technical change of 5 per cent per year.

To check the consistency of two sets of factual assumptions, both sets of assumptions must be translated into the same framework and compared within that framework. In view of the one-toone correspondence between indexes of embodied technical change and indexes of disembodied technical change, it is completely immaterial which framework is used for the comparison. If the two sets of factual assumptions are not consistent, the factual question that must be answered is not whether embodied or disembodied technical change is an appropriate model of reality. We have already demonstrated that both types of technical change imply the same model of reality, that is, both models have the same set of factual implications. The factual question to be answered is, in our example, whether disembodied change takes place at 4 per cent per year or 5 per cent per year. 
We have already illustrated the equivalence of embodied and disembodied technical change by calculating indexes of each type from a given set of data. It may be useful to illustrate this equivalence further by calculating the amount of investment required to attain a given amount of economic growth using models of embodied and disembodied technical change, together with a set of assumptions that is factually consistent. This puted using expression (9). In comparing factual assumptions about embodied technical change with factual assumptions about disembodied technical change, it is important to keep in mind that indexes of technical change and the corresponding indexes of capital input come in pairs. Choosing a particular index of the rate of technical change from among all those consistent with a given body of data implies the choice of a

TABLE 4

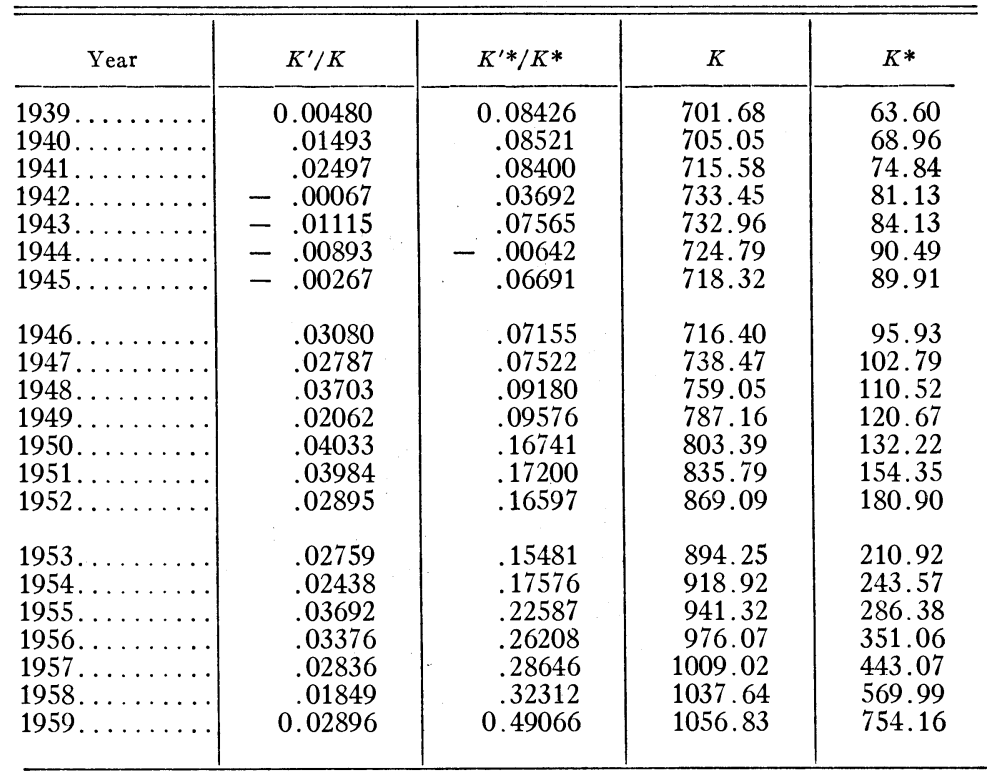

type of calculation can be done for very complicated sets of factual assumptions. The general procedure is to state the set of factual assumptions in such a way that the basic data that underlie expression (9) are specified. Then, for a given time path of the data and of the index of embodied technical change, expression (9) may be used to compute the equivalent time path of the index of disembodied technical change. Alternatively, for a given time path of the data and of the index of disembodied technical change, the equivalent time path of the index of embodied technical change may be com- particular index of capital input. Indexes of capital input corresponding to the indexes of embodied and disembodied technical change of Table 2 are presented in Table 4. Table 4 contains the rates of growth of capital and surrogate capital, $K^{\prime} / K$ and $K^{\prime *} / K^{*}$, as well as the corresponding indexes of capital and surrogate capital, $K$ and $K^{*}$, respectively.

To simplify the calculation of the amount of investment required for a given amount of economic growth, which is only intended to serve as an illustration, we assume that the calculation is to be done for a set of factual assumptions 
in which investment, capital, and indexes of technical change are growing at constant exponential rates. In the long run the rate of growth of investment and the rate of growth of capital are equal; we assume linal these rates of growth are equal at the outset. Finally, we assume that all value shares are constant.

For a model of disembodied technical change the rate of growth of output is a weighted average of the rates of growth of capital and labor plus the rate of growth of the index of disembodied technical change. The rate of growth of capital is equal to the ratio of investment to capital less the rate of replacement. Taking the value shares as those that prevailed in 1959, assuming that the rate of growth of labor is the same as in 1959 and taking the rate of replacement to be 0.025 per year, we suppose that the rate of disembodied technical change is 0.025 per year and the rate of growth of output is 0.03 per year. The implied ratio of gross investment to capital is 0.028 . To raise the rate of growth of output by one percentage point to 0.04 per year, an increase of 33 per cent, the required ratio of gross investment to capital is 0.056 , an increase of 100 per cent.

For a model of embodied technical change the rate of growth of output may be expressed in two ways. First, the rate of growth is a weighted average of the rates of growth of surrogate capital and labor. Alternatively, if the rate of embodied technical change is constant and the rates of growth of investment and capital stock are equal, the rate of growth of output is a weighted average of the rates of growth of capital and labor plus the relative share of capital less the relative share of investment multiplied by the rate of embodied technical change. Under the factual assumptions we have made, a rate of embodied technical change of 0.13 per year corresponds to a rate of disembodied technical change of 0.025 per year. At a rate of growth of output of 0.03 per year, the implied ratio of gross investment to capital is, of course, the same as before, 0.028. To raise the rate of growth of output by one percentage point, that is, to 0.04 per year, an increase of 33 per cent, the required ratio of gross investment to capital is 0.056 , an increase of 100 per cent. This result illustrates the fact that calculations of the amount of investment required to attain a given amount of economic growth, using models of embodied and disembodied technical change together with a set of assumptions that is factually consistent, give identical results for the two models.

\section{MATHEMATICAL APPENDIX}

In this Appendix we present a formal analysis of the relationship between $P$, the index of total factor productivity, and $Q$, the relative error in measurement of the price of investment goods or the reciprocal of the index of the quality of investment goods. The data given at the outset include six basic time series and the rate of replacement of capital goods, $\delta$. The six basic time series are prices and quantities of investment-goods output, consumption-goods output, and labor input. From these data the shares of investment goods, consumption goods, capital services, and labor services in the value of total output may be computed.

1. The first problem is to compute $P$, the index of total factor productivity, from the six basic time series. Beginning with the definition of the index of total factor productivity,

$$
v_{I} \frac{I^{\prime}}{I}+v_{C} \frac{C^{\prime}}{C}=\frac{P^{\prime}}{P}+w_{K} \frac{K^{\prime}}{K}+w_{L} \frac{L^{\prime}}{L},
$$

and using the fact that

$$
K^{\prime}=I-\delta K
$$


the definition may be written in the form:

$$
\begin{aligned}
v_{I} \frac{I^{\prime}}{I}+v_{C} \frac{C^{\prime}}{C}+w_{K} \delta-w_{L} \frac{L^{\prime}}{L}-\frac{P^{\prime}}{P} \\
=\frac{e^{\delta t} w_{K} I}{\int_{-\infty}^{t} e^{\delta s} I(s) d s} .
\end{aligned}
$$

Now, letting $a, b$, and $c_{P}$ be given functions of time, defined as

$$
\begin{aligned}
& a=v_{I} \frac{I^{\prime}}{I}+v_{C} \frac{C^{\prime}}{C}+w_{K} \delta-w_{L} \frac{L^{\prime}}{L}, \\
& b=w_{K} I,
\end{aligned}
$$

and

$$
c_{P}=-1 \text {, }
$$

we may rewrite the definition in the form:

$$
\int_{-\infty}^{t} e^{\delta s} I(s) d s=\frac{b e^{\delta t} P}{a P+c_{P} P^{\prime}} .
$$

Differentiating with respect to time we obtain:

$$
\begin{gathered}
{\left[I a^{2}-\left(b^{\prime}+\delta b\right) a+a^{\prime} b\right] P^{2}+\left[2 I a c_{P}\right.} \\
\left.-\left(b^{\prime}+\delta b\right) c_{P}+b c_{P}^{\prime}\right] P P^{\prime}+\left[I c_{P}^{2}\right. \\
\left.-b c_{P}\right] P^{\prime 2}+b c_{P} P P^{\prime}=0 .
\end{gathered}
$$

Letting $R=P^{\prime} / P$, we may write

$$
R^{\prime}=d_{P}+e_{P} R+f_{P} R^{2},
$$

where

$$
\begin{aligned}
& d_{P}=a\left(I \frac{a}{b}-\frac{b^{\prime}}{b}-\delta+\frac{a^{\prime}}{a}\right), \\
& e_{P}=-2 I \frac{a}{b}+\frac{b^{\prime}}{b}+\delta,
\end{aligned}
$$

and

$$
f_{P}=\frac{1}{w_{K}} .
$$

We conclude that the rate of growth of the index of total factor productivity satisfies an ordinary second-degree differential equation with variable coefficients that depend on the six basic time series.

2. The second problem is to compute $Q$, the relative error in the price of investment goods or the reciprocal of the index of quality of investment goods, from the six basic time series.
Beginning with the definition of the index of the quality of investment goods,

$$
v_{I} \frac{I^{\prime *}}{I^{*}}+v_{C} \frac{C^{\prime}}{C}=w_{K} \frac{K^{\prime *}}{K^{*}}+w_{L} \frac{L^{\prime}}{L},
$$

where $Q I^{*}=I$ and $K^{\prime *}=I^{*}-\delta K^{*}$, the definition may be written in the form:

$$
\begin{aligned}
v_{I} \frac{I^{\prime}}{I}+v_{C} \frac{C^{\prime}}{C}+w_{K} \delta & -w_{L} \frac{L^{\prime}}{L}-v_{I} \frac{Q^{\prime}}{Q} \\
& =\frac{e^{\delta t} w_{K} I}{Q \int_{-\infty}^{t} e^{\delta s} \frac{I(s)}{Q(s)} d s} .
\end{aligned}
$$

Letting $a, b$, and $c_{Q}$ be given functions of time, with $a$ and $b$ defined as before and $c_{Q}$ defined as $c_{Q}=-v_{I}$, we may rewrite the definition in the form:

$$
\int_{-\infty}^{t} e^{\delta s} \frac{I(s)}{Q(s)} d s=\frac{b e^{\delta t}}{a Q+c_{Q} Q^{\prime}} .
$$

Differentiating with respect to time we obtain:

$$
\begin{gathered}
{\left[I a^{2}-a\left(b^{\prime}+\delta b\right)+a b\right] Q^{2}+\left[2 I a c_{Q}\right.} \\
\left.-\left(b^{\prime}+\delta b\right) c_{Q}+a b+b c_{Q}^{\prime}\right] Q^{\prime} Q \\
+I c_{Q}^{2} Q^{\prime 2}+b c_{Q} Q Q^{\prime}=0 .
\end{gathered}
$$

Letting $S=Q^{\prime} / Q$, we may write

where

$$
S^{\prime}=d_{Q}+e_{Q} S+f_{Q} S^{2},
$$

$$
\begin{aligned}
d_{Q} & =\frac{a}{v_{I}}\left(I \frac{a}{b}-\frac{b^{\prime}}{b}-\delta+\frac{a^{\prime}}{a}\right)=\frac{d_{P}}{v_{I}} \\
e_{Q} & =-2 I \frac{a}{b}+\frac{b^{\prime}}{b}+\delta+\frac{a-v_{I}^{\prime}}{v_{I}} \\
& =e_{P}+\frac{a-v_{I}^{\prime}}{v_{I}}
\end{aligned}
$$

and

$$
f_{Q}=\frac{v_{I}-w_{K}}{w_{K}}=\left(v_{I}-w_{K}\right) f_{P} .
$$

We conclude that the rate of growth of the index of the quality of investment goods satisfies an ordinary second-degree differential equation with variable coefficients that depend on the six basic time series. The form of the equation is strictly analogous to that for the index of total factor productivity; the coefficients in both equations depend on the same basic time series. 
3. To obtain the differential equation governing $Q$, the reciprocal of the index of the quality of investment goods, where "surrogate" capital is introduced but "surrogate" investment is not, we omit the term $-v_{I}\left(Q^{\prime} / Q\right)$ from the definition of the index of the quality of investment goods. The resulting definition is

$$
\begin{aligned}
v_{I} \frac{I^{\prime}}{I}+v_{C} \frac{C^{\prime}}{C}+w_{K} \delta & -w_{L} \frac{L^{\prime}}{L} \\
& =\frac{e^{\delta t} w_{K} I}{Q \int_{-\infty}^{t} e^{\delta s} \frac{I(s)}{Q(s)} d s},
\end{aligned}
$$

or, employing the notation introduced above,

$$
\int_{-\infty}^{t} e^{\delta s} \frac{I(s)}{Q(s)}=\frac{b e^{\delta t}}{a} .
$$
tain:

Differentiating with respect to time we ob-

$$
Q^{\prime}+Q\left(I \frac{a}{b}-\frac{b^{\prime}}{b}-\delta+\frac{a^{\prime}}{a}\right)=0 .
$$

Letting $S=Q^{\prime} / Q$, as before, we may write

$$
0=d_{Q}+e_{Q} S,
$$

where

and

$$
d_{Q}=I \frac{a}{b}-\frac{b^{\prime}}{b}-\delta+\frac{a^{\prime}}{a}=\frac{d_{P}}{a}
$$

$$
e_{Q}=1 \text {. }
$$

We conclude that in this case the rate of growth of the index of the quality of investment goods satisfies a linear equation with variable coefficients that depend on the six basic time series.

4. The final problem is to show that any pair of indexes, $P$ and $1 / Q$, constructed from the six basic time series, will satisfy equation (9) of the text, namely:

$$
\begin{aligned}
& \frac{P^{\prime}}{P}=v_{I} \frac{Q^{\prime}}{Q} \\
& +\mathfrak{l}_{K}\left[\frac{I}{\int_{-\infty}^{t} e^{-\delta(t-s)} \frac{Q(t)}{Q(s)} I(s) d s}\right. \\
& \left.-\frac{I}{\int_{-\infty}^{t} e^{-\delta(t-s)} I(s) d s}\right] \text {. }
\end{aligned}
$$

To verify this equality we replace each of the integrals occurring on the right-hand side by the corresponding expression from the definitions of the indexes $P$ and $1 / Q$ :

$$
\begin{aligned}
\frac{P^{\prime}}{P}=v_{I} \frac{Q^{\prime}}{Q}+w_{K}\left[\frac{I}{b}\left(a+c_{Q} \frac{Q^{\prime}}{Q}\right)\right. & \\
& \left.-\frac{I}{b}\left(a+c_{P} \frac{P^{\prime}}{P}\right)\right] .
\end{aligned}
$$

Using the definitions of $a, b, c_{P}$, and $c_{Q}$ given above, the equality is easily verified.

We conclude that any pair of indexes, $P$ and $1 / Q$, constructed from the six basic time series, will satisfy equation (9) of the text. To be more precise: Both of the indexes satisfy ordinary second-order differential equations. Hence, the definition of each index generates a two-parameter family of indexes. The parameters that generate a given member of each family may be interpreted as the initial value of the index and the initial value of the corresponding capital stock. Any pair of indexes, $P$ and $1 / Q$, consisting of one member of each of the families, satisfies equation (9) of the text. There is a one-toone correspondence between the families of indexes constructed from a given set of data.

5. Similarly, we may show that pairs of indexes, $P$ and $1 / Q$, where the index of the quality of investment goods, $1 / Q$, is constructed omitting "surrogate" investment, will satisfy equation (10) of the text, namely:

$$
\begin{array}{r}
\frac{P^{\prime}}{P}=w_{K}\left[\frac{I}{\int_{-\infty}^{t} e^{-\delta(t-s)} \frac{Q(t)}{Q(s)} I(s) d s}\right. \\
\left.-\frac{I}{\int_{-\infty}^{t} e^{-\delta(t-s)} I(s) d s}\right]
\end{array}
$$

Using the definitions of the indexes $P$ and $Q$ as before,

$$
\frac{P^{\prime}}{P}=w_{K}\left[I \frac{a}{b}-\frac{I}{b}\left(a+c_{P} \frac{P^{\prime}}{P}\right)\right] .
$$

This equality is easily verified directly from the definitions of $a, b$, and $c_{P}$. 


\section{REFERENCES}

Abramovitz, Moses. "Economic Growth in the United States," American Econ. Rev., LII, No. 4 (September, 1962), 762-82.

Arrow, K. J., Chenery, H. B., Minhas, B. S., and Solow, R. M. "Capital-Labor Substitution and Economic Efficiency," Rev. Econ. Statis., XLIII, No. 3 (August, 1961), 225-50.

Clemhout, S. "The Ratio Method of Productivity Measurement," Econ. J., LXXIII, No. 290 (June, 1963), 358-60.

Denison, E. F. "Measurement of Labor Input: Some Questions of Definition and the Adequacy of Data," in Conference on Research in Income and Wealth, Output, Input, and Productivity Measurement. ("Studies in Income and Wealth," Vol. XXV.) Princeton, N.J.: Princeton University Press, 1961, pp. 347-72.

- "The Sources of Economic Growth in the United States and the Alternatives before Us." (Supplementary Paper No. 13.) New York: Committee for Economic Development, 1962.

—. "The Unimportance of the Embodied Question," American Econ. Rev., LIV, No. 2, Part 1 (March, 1964), 90-93.

Divisia, F. "L'indice monétaire et la théorie de la monnaie," Rev. d'écon. polit., XXXIX, Nos. 4, 5, 6 (1925), 842-61, 980-1008, 112151.

$$
\text { Ibid., LX, No. } 1 \text { (1926), 49-81. }
$$

Économique rationnelle. Paris: Gaston Doin et Cie, 1928.

- Exposés d'ćconomique, Vol. I. Paris: Dunod, 1952.

Domar, E. D. "On the Measurement of Technological Change," Econ. J., LXXI, No. 284 (December, 1961), 709-29.

—. "Total Productivity and the Quality of
Capital," J.P.E., LXXI, No. 6 (December, 1963), 586-88.

Frisch, Ragnar. "Annual Survey of General Economic Theory: The Problem of Index Numbers," Econometrica, IV, No. 1 (January, 1936), 1-38.

Gordon, R. A. "Price Changes: Consumers' and Capital Goods," American Econ. Rev., LI, No. 5 (December, 1961), 937-57.

Hardy, G. H., Littlewood, J. E., and Polya, G. Inequalities. $2 \mathrm{~d}$ ed. Cambridge: Cambridge University Press, 1952.

Hicks, J. R. Value and Capital. 2d ed. Oxford: Oxford University Press, 1946.

Kendrick, J. W. Productivity Trends in the United States. Princeton, N. J.: Princeton University Press, 1961.

Kendrick, J. W., and Sato, Ryuzo. "Factor Prices, Productivity, and Growth," American Econ. Rev., LIII, No. 5 (December, 1963), 974-1003.

Solow, R. M. "Technical Change and the Aggregate Production Function," Rev. Econ. Statis., XXXIX, No. 3 (August, 1957), 31220.

- "Investment and Technical Progress," in K. J. Arrow, S. Karlin, and P. Suppes (eds.), Mathematical Methods in the Social Sciences, 1959. Stanford, Calif.: Stanford University Press, 1960, pp. 89-104.

Tinbergen, J. "On the Theory of Trend Movements," in L. H. Klaassen, L. M. Koyck, and H. J. Witteveen (eds.), Jan Tinbergen Selected Papers. Amsterdam: North-Holland, 1959, pp. 182-221 (originally published in German as "Zur Theorie der langfristigen Wirtschaftsentwicklung," Weltwirtschaftliches Archio, LV, No. 1 [1942], 511-49).

Wold, H. Demand Analysis. New York: John Wiley \& Sons, 1953. 